\title{
Flexible Mode Control of Grid Connected Wind Energy Conversion System Using Wavelet
}

\author{
Bhavna Jain, Sameer Singh, Shailendra Jain, and R. K. Nema
}

MANIT, Bhopal 462003, India

Correspondence should be addressed to Bhavna Jain; jain_bhavna69@yahoo.com

Received 30 June 2014; Revised 21 January 2015; Accepted 29 January 2015

Academic Editor: Ahmet Z. Sahin

Copyright (C) 2015 Bhavna Jain et al. This is an open access article distributed under the Creative Commons Attribution License, which permits unrestricted use, distribution, and reproduction in any medium, provided the original work is properly cited.

\begin{abstract}
Small wind turbine systems offer services to critical loads during grid faults and also connected back to grid in normal condition. The connection of a wind energy conversion system to the grid requires a robust phase locked loop (PLL) and continuous monitoring of the grid conditions such as overvoltage, undervoltage, overfrequency, underfrequency, and grid outages. This paper describes a flexible control operation to operate a small wind turbine in both stand-alone mode via planned islanding and grid connected mode as well. In particular, a proper monitoring and control algorithm is required for transition between the modes. A wavelet based energy function is used for detection of grid disturbances as well as recovery of grid so that transition between the modes is made. To obtain good power quality LCL filter is used to reduce ripples. PLL is used for synchronization whenever mode changes from stand-alone to grid connected. Simulation results from a $10 \mathrm{~kW}$ wind energy conversion system are included to show the usefulness of the proposed methods. The control method is tested by generated gate pulses for single phase bridge inverter using field programmable gate array (FPGA).
\end{abstract}

\section{Introduction}

Due to awareness for pollution free environment, depletion of conventional energy sources, and growing demand of energy worldwide, the government of different countries has been promoting electricity generation from renewable sources. Renewable energy sources are becoming an important option to meet the growing demand of energy and simultaneously help in controlling of greenhouse gas emission caused by conventional energy sources. Another major benefit of renewable energy source is that it can work in stand-alone mode to fulfil the customer demand and can work as grid connected system to supply extra power generated to grid, hence, increasing the reliability of power supply.

Out of all renewable sources, wind power generation technology has been grown up, in the beginning with few KW to multi-MW capacity wind turbine manufactured and installed. An attractive idea of universal mode of small wind turbine (SWT) has been implemented in which they can either operate as stand-alone mode or can work in grid connected mode $[1,2]$. Small wind turbines can be used in rural areas in developed countries where grid is not available [3].
The amplitude and frequency of generated voltage of wind plants vary according to speed of wind [4]. Hence, power electronics interfaces are used to convert generated voltage to a fixed dc voltage, which can later be either stored or converted into required ac voltage and frequency. Grid connected wind energy conversion systems are more in trend. In case of grid faults, WECS system connected to grid can be safely islanded to serve critical loads connected to it.

When a small wind turbine unit is connected to the grid, the voltage and frequency at the point of common coupling are controlled by the grid. However, in case of weak grids, voltage sags and disturbances may occur when WECS is interfaced to grid. In such situation, the wind unit must support to the grid voltage. A wind energy conversion system can work in two different modes; they are grid connected and standalone modes. The stand-alone/islanding mode is a situation in which the WECS is isolated from the utility grid when grid disturbances due to network fault are cropped up. A monitoring unit is used to achieve it. This unit will help in islanded operation of WECS in a planned manner when voltage magnitude crosses the threshold value. 


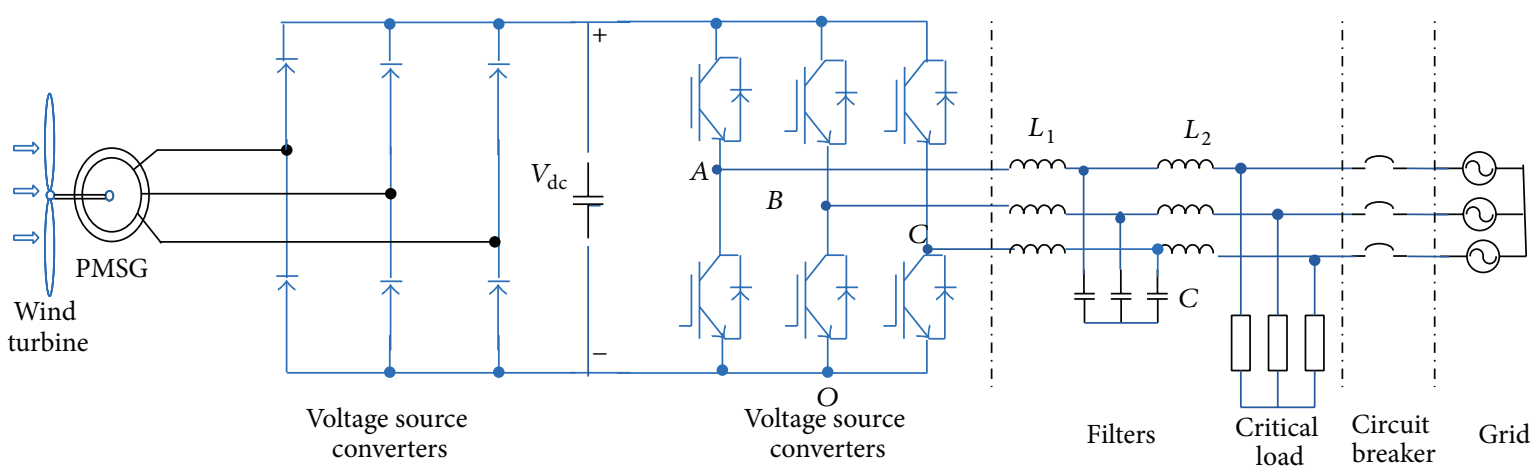

FIgURE 1: Schematic diagram of WECS interfacing to grid.

Authors in [5] verified experimentally the control algorithm applied in SWT working in both stand-alone and grid connected modes. Performance of synchronization algorithm is also checked which is used to connect DC/AC converter back to grid after recovery from disturbance. A novel method novel based on PLL is proposed by Teodorescu and Blaabjerg for grid failure detection and flexible mode switching automatically in which the phase difference between the grid and the inverter is used to determine grid failure and recovered from fault [3]. Jang and Kim presented three papers starting in an algorithm improved successively which utilizes four system parameters voltage magnitude, frequency, phase, and total harmonic distortion (THD) of current for islanding detection. The method monitors changes in four parameters and detects islanding by logical rules [6-8]. During disturbances many system parameters change significantly. Hence selection of most vulnerable system parameter and selection of threshold value is very challenging task for effective detection of disturbances. Many authors have implemented different methods based on wavelet transform (WT) for detection of power quality disturbance [9-14]. Wavelet energy entropy, variance, standard deviation, mean, and wavelet energy are various statistical features suitable for detection of power quality disturbances and an islanding event.

In this paper a WECS is developed using SIMULINK with a flexible mode control strategy and synchronization algorithm to allow dual mode operation of it as and when required. A seamless transfer between the modes is realized by opening and closing of the circuit breaker as shown in Figure 1 which disconnects/connects the WECS from/to the main grid [15]. Once the WECS is isolated from the main grid, WECS will be responsible for maintaining the voltage and frequency while supplying to load. During autonomous operation it is essential that inverters should not be overloaded. Simultaneously system must ensure that the changes in load are handled by inverters properly in a control manner.

The DC/AC converter of WECS is connected to grid to inject active and reactive power. Mainly current-controlled voltage source converter (VSC) is used in grid connected mode $[16,17]$. Conversely, voltage controlled VSC is used when the WECS works in the stand-alone mode. To regulate voltage and maintain it constant is the major responsibility of control method used in isolated mode of WECS. During grid disturbances, the detection method based on wavelet energy function is used to change of mode of operation for grid connected to isolated mode of WECS and vice versa. A circuit breaker is used for this and will switch between the modes on the basis of signal received from control method used.

The main objective of this paper is to control the flexible mode operation of control grid connected wind energy conversion system using wavelet energy based function. Since the wind energy conversion system has been competent to operate in both grid connected mode and stand-alone mode according to the grid conditions, the control design is a bit tricky. This paper is presented as follows. Section 2 describes the inverter control in stand-alone mode of operation. Then, control methods for grid connected operating mode including the PLL design and current regulation of the inverter are explained in Section 3. Use of wavelet energy function for detecting the status of grid is described in Section 4. In Section 5 the verification of the control methods is done through simulation results. The control scheme implemented in WECS is tested using FPGA in Section 6. Finally, conclusions are drawn in Section 7.

\section{Inverter Control in Stand-Alone Mode of WECS}

Electrical power available at the electrical generator output of the wind energy conversion system is not sinusoidal in nature. To get the sinusoidal voltage at supply frequency and to keep the output power optimally constant, power electronic interfacing is done between generator and grid/load as shown in Figure 2. In general, a power electronic interface device is a combination of a rectifier, an energy storage device to regulate the DC-link voltage and an inverter.

Voltage source inverter of load side is responsible for providing controlled output voltage in terms of frequency and amplitude [18, 19]. At load side inverter, appropriate control method is applied for generating switching pulses of inverter to produce output of required magnitude and frequency. To achieve it the control method has an output voltage controller using any modulation technique. Here space vector modulation method is implemented. The schematic diagram of the control method is shown in Figure 3. 


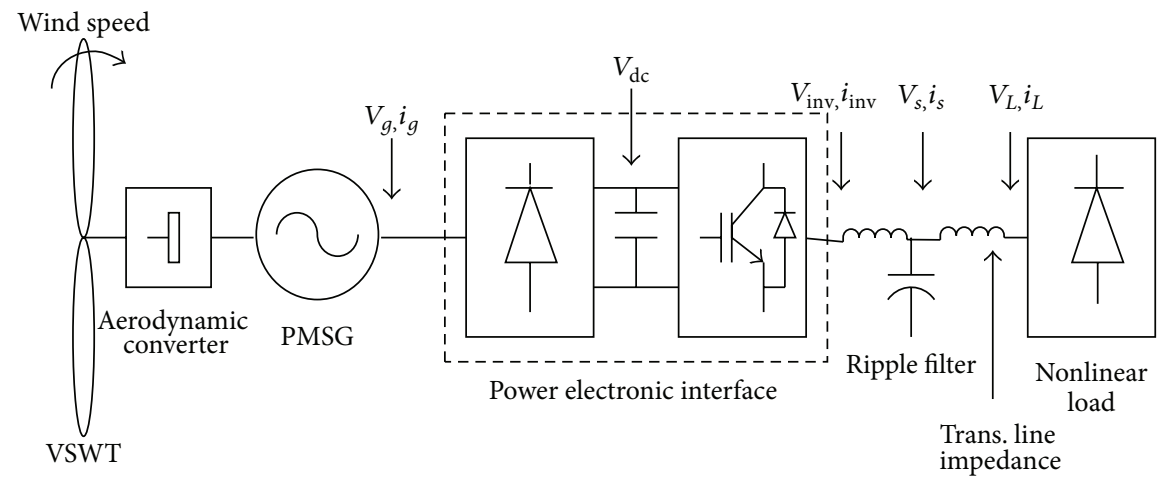

FIGURE 2: Power transfer stages in isolated WECS.

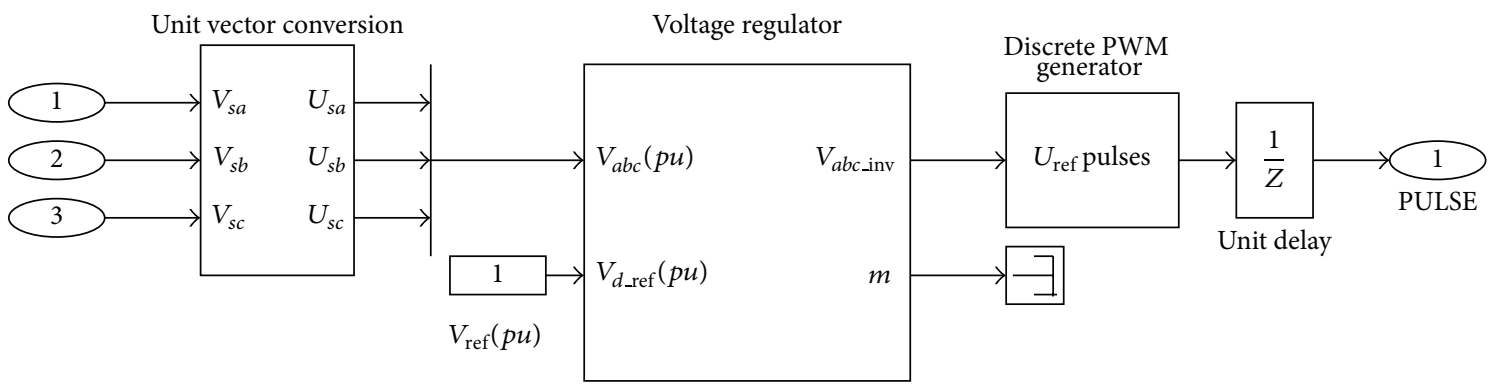

FIGURE 3: Simulation block diagram for SVPWM to generate gate pulses.

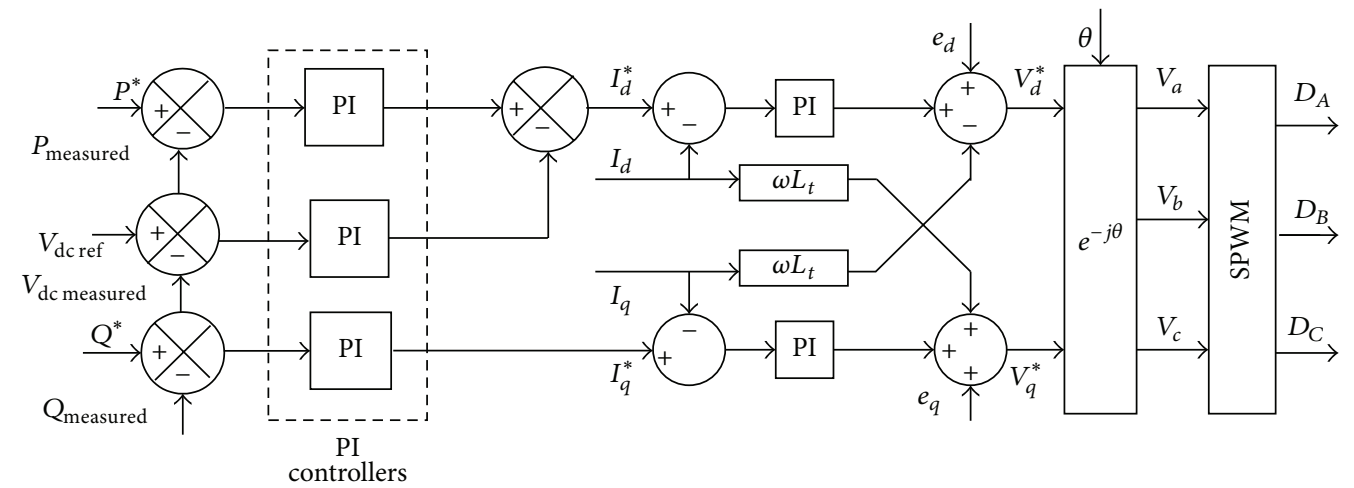

FIGURE 4: Grid side inverter control.

In space vector PWM, 3-phase sinusoidal modulating signal gets transformed into a revolving voltage vector with a constant magnitude and angular frequency. Here, the constant voltage magnitude is magnitude of desire voltage to be produced and angular frequency is the sampling frequency. In space vector based PWM, instead of three modulating signals for 3-phase, a revolving voltage vector is used as a voltage reference. This voltage reference vector is sampled once in every subcycle $T_{s}$ and sampled voltage vector gives the voltage command for the given subcycle.

\section{Inverter Control of WECS in Grid Connected Mode}

Voltage oriented control (VOC) is mostly used for grid side voltage source inverter as shown in Figure 4. A phase locked loop (PLL) is used to find out grid angle $\theta$ which is used for transformation of inverter output currents and output voltages in synchronous reference frame. To obtain better response of inverter, it has been selected to decouple active and reactive power. The active power depends on the $d$ axis current component. Similarly, reactive power and $q$-axis current component are directly related. Therefore, the $d$-axis PI controller controls active power, and $q$-axis PI controller controls reactive power.

Grid currents are converted in synchronous reference frame currents $i_{d}, i_{q}$ to provide separate control for active and reactive power. High power factor and sinusoidal grid currents can be obtained by doing so [20].

In order to operate under synchronization with grid, the system uses three PI controllers. The DC-link voltage controller is used for calculating $d$-axis reference current to 


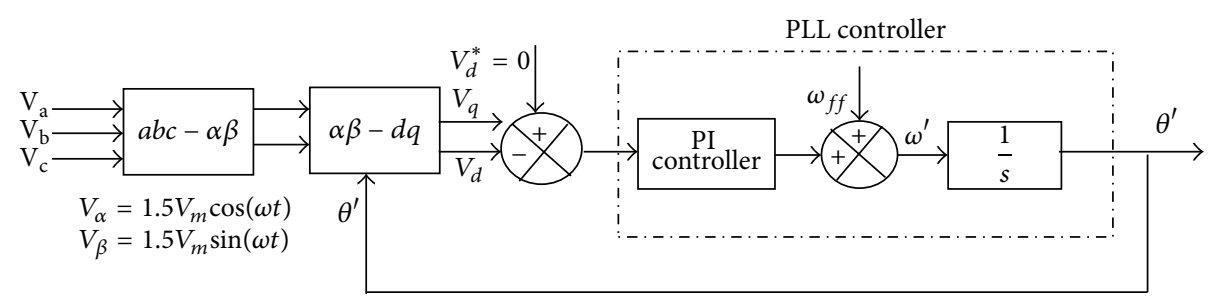

FIGURE 5: Block diagram of phase locked loop based on synchronous reference frame.

control active power. The $q$-axis reference can be set to zero to get unity power factor. By using PI controllers for controlling the errors in $d$-axis and $q$-axis currents, the control voltages are generated for the 3- $\emptyset$ voltage source inverter in $P Q$ control method as shown in Figure 4 and are given by

$$
\begin{aligned}
& V_{d}^{*}=V_{d}+\omega L_{t} i_{q}-e_{d} \\
& V_{q}^{*}=V_{q}-\omega L_{t} i_{d}-e_{q}
\end{aligned}
$$

where $L_{t}$ is the total inductance on the grid side inverter and $e_{d}$ and $e_{q}$ are $d-q$ components of grid side voltage vector.

Tuning of PI controllers must be done accurately to obtain better control of DC-link voltage, active power, and reactive power. The feedforward and cross coupling terms used in generation of reference voltage vector in synchronous reference frame help out in system linearization and make controller design easier. The reference voltages $V_{d}^{*}$ and $V_{q}^{*}$ are further transformed into and used to generate inverter gate pulses through a SVPWM algorithm. LCL filter is used to improve the power quality at the inverter output.

\section{Grid Status Monitoring and Transition of Modes}

4.1. Phase Locked Loop. The utility grid status monitoring must be done continuously in real time, to ensure good quality power supply to loads. The grid status includes sensing fault, overvoltage, and undervoltage conditions. Outage detection is carried out in every sampling cycle by comparing the instantaneous grid voltage. The block diagram of the three-phase PLL used for synchronization in the grid connected mode is as shown in Figure 5. A resonant filter can be added to make standard PLL more robust in case of unbalance and voltage harmonics.

In case of grid failure, islanded cannot be avoided. Hence suitable method must be used to detect grid failure. For connected to grid again when grid returns to its normal condition, use of a synchronization algorithm is necessary prior to transition of mode from stand-alone to grid connected. The flowchart shown in Figure 6 is proposed for islanding detection and further for transition from grid connected mode of WECS to stand-alone mode. In case of grid disturbances,

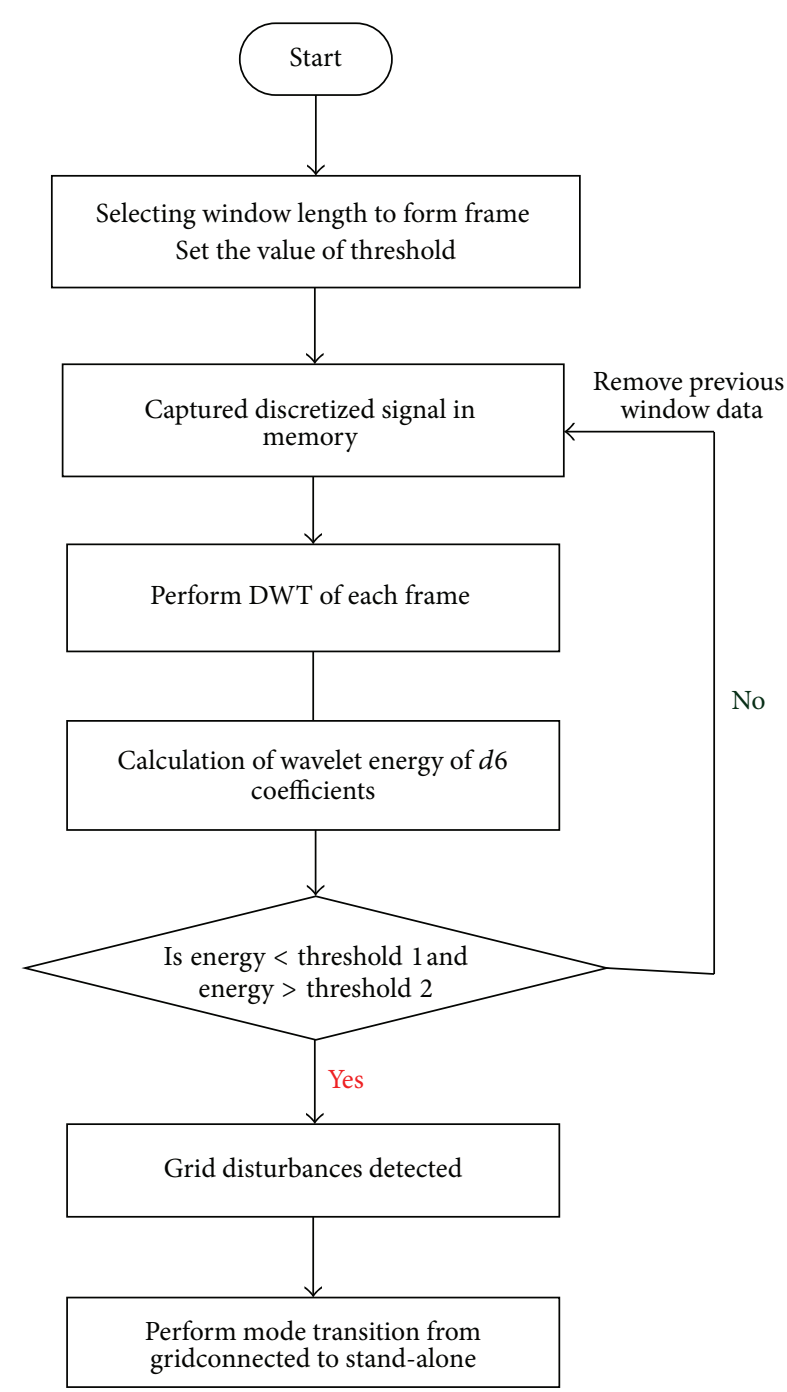

Figure 6: Flowchart for detection of grid faults/islanding.

mode change of WECS from grid connected to stand-alone is performed in the following steps.

(1) Identify grid condition using power quality monitoring.

(2) Generate a signal to turn off circuit breaker in case of grid fault. 


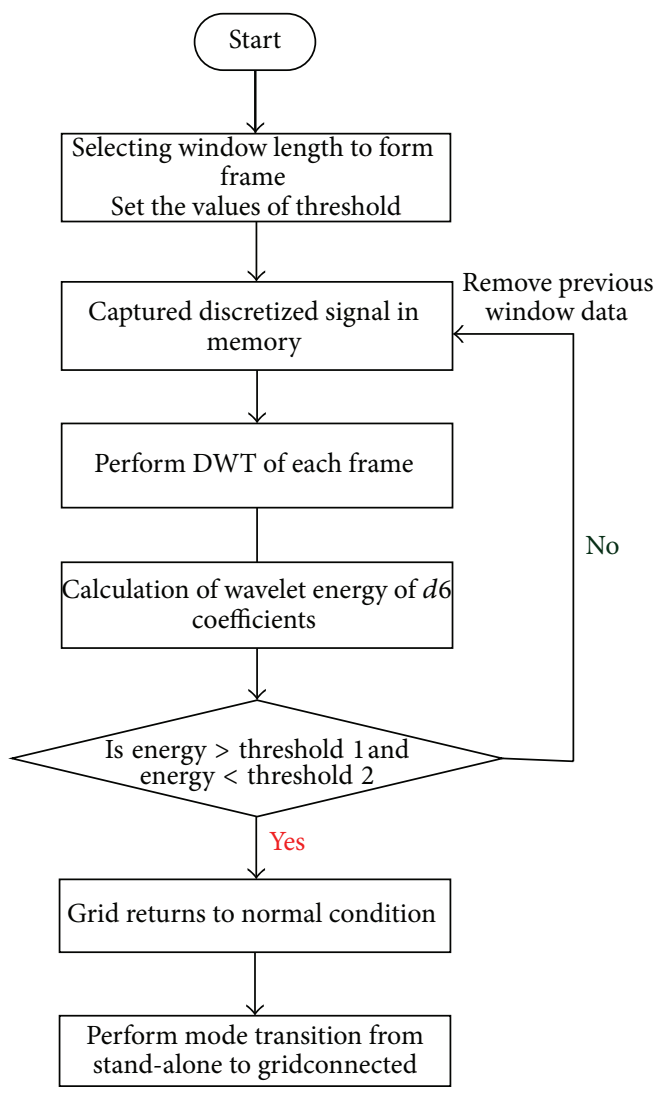

FIGURE 7: Flowchart for returning to grid normal operation.

(3) Mode transition can be done as soon as the circuit breaker turns off. Change the grid connected mode of WECS to stand-alone mode.

(4) In case of stand-alone mode, the control strategy will be voltage controlled. In voltage controlled mode of load side inverter, the reference value used for voltage will be last value of grid voltage when mode transition takes place.

The flowchart shown in Figure 7 is proposed for detection of grid recovery and transition from stand-alone mode to grid connected mode of WECS.

4.2. Discrete Wavelet Transform. Discrete wavelet transform (DWT) converts a time domain discretized signal into its corresponding wavelet domain. Principally, the discrete wavelet transformation has two-phase determination of wavelet coefficients and calculation of detailed and approximated version of the original signal, in different scales of resolutions in the time domain. In filtering process the original signal is passed through two complementary filters and produces approximate and detail coefficients. To extend the frequency resolution, decomposition of signal is done repeatedly and signal can be realized into two lower frequency ranges. This process is known as multiresolution analysis (MRA) and goal of MRA is to represent a complex signal by several simple signals to study them separately.
4.3. Frame Length. Coefficients of wavelet transform represent the energy of the signal. These coefficients will be used to measure the magnitude of the disturbance in distorted signal. In real time application wavelet transform can be used as a monitoring tool when it becomes essential to detect disturbances in minimum time. For such cases distorted signal is processed through time window of fixed length frame. Length of the frame means the number of sample points of discrete data signal for which wavelet energy has to be calculated. The time window move forward along the signal and wavelet energy is calculated for each frame. Frame length decides the response time of the method. If length of the frame is long it will take more time in calculation and response time will get delayed. Sampling frequency, size of buffer, and level of decomposition are three main factors which must be wisely selected according to application. A fixed frame length of sample points 128 is used in this paper to obtain fast response time. The sampling frequency selection has been done according to Parseval's theorem and decomposition has been done into 6th level.

4.4. Wavelet Energy. The discrete wavelet divides a signal into approximated and detailed version of the original signal, in different scales of resolutions in the time domain using lowpass and high-pass filters. Decomposition of approximate version can be repeated to obtain signal in required frequency subbands with number of approximate and detail coefficients. Sum of coefficients square at a particular level represent the energy of the signal at that level. These coefficients will be used to compute the level of the disturbance in distorted signal. Wavelet energy measure based on wavelet analysis is able to observe the unsteady signal and complexity of the system at time-frequency plane. The mother wavelet function selected is $\mathrm{db}$ and scale factor 2 that is according to literature reviews. The signal is decomposed into 6th level. Hence, cD6 coefficients will represent the fundamental frequency component of the signal and coefficients energy will be calculated by using

$$
E_{j}=\sum_{k=1}^{N}\left|D_{j k}\right|^{2}, \quad j=1,2, \ldots, l,
$$

where $D_{j k}$ is the value of wavelet detail coefficients obtained in decomposition from level 1 to level $J . N$ is the total number of the coefficients at each decomposition level and $E_{j}$ is the energy of the detail coefficients at decomposition level $j$.

4.5. Deciding Threshold. The most important part of monitoring algorithm is deciding the setting for threshold level. The value should be selected to change mode of WECS whenever voltage of any phase crosses the standard limits such as voltage dip of less than 0.8 pu or voltage swell of magnitude more than $1.2 \mathrm{pu}$ Simultaneously, it should not cause unnecessary false tripping of circuit breaker in case of small voltage dip or swell. It is the value of wavelet energy calculated for output voltage signal (grid voltage) under normal grid condition plus a variation allowed as per standards. For calculating the threshold a reference signal of same frame 


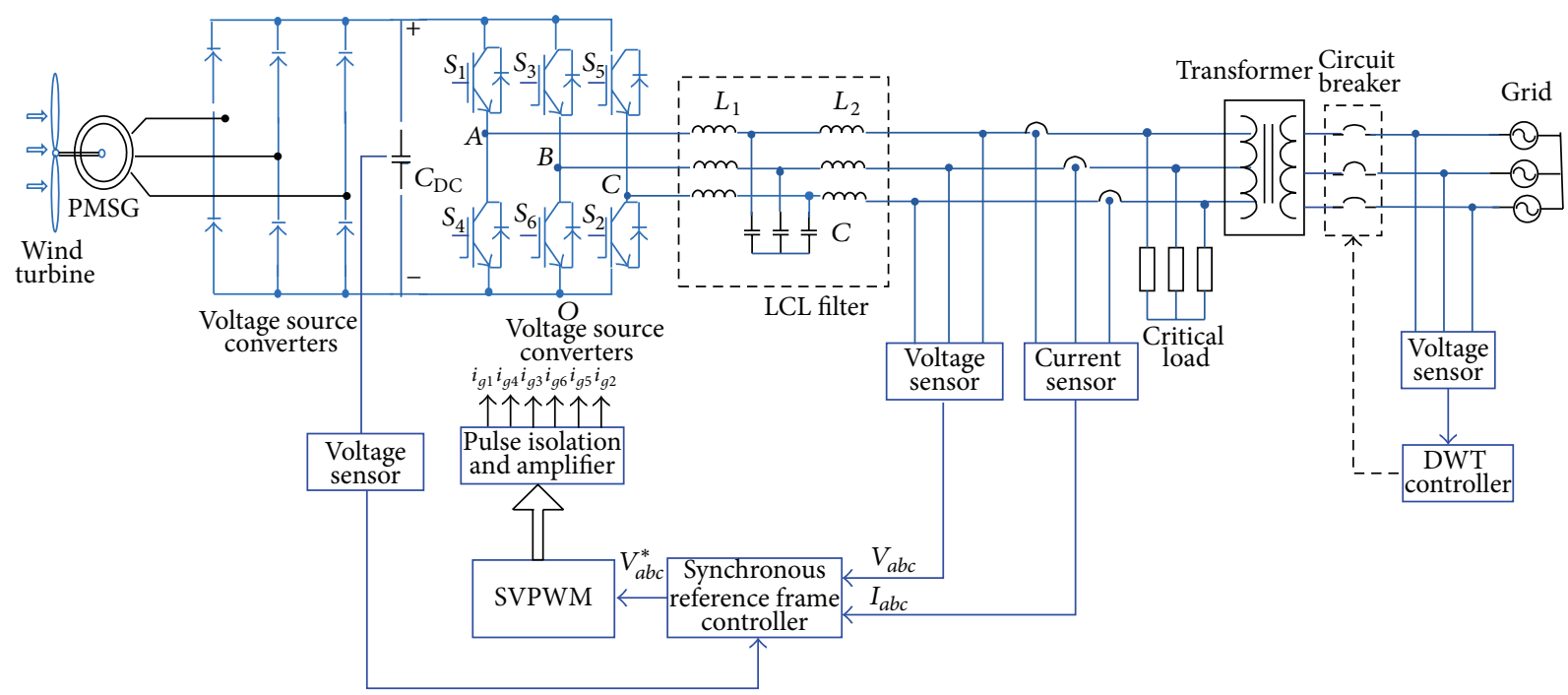

FIGURE 8: Schematic diagram of WECS connected to grid.

TABLE 1: Parameters selection for proposed method.

\begin{tabular}{lccc}
\hline Parameter & Peak voltage level $(V)$ & Wavelet energy $\left(V^{2}\right)$ & Normalized wavelet energy \\
\hline Peak voltage of grid & 325 & $2.3 * e 6 / 10^{5}$ & 23 \\
Permissible limit of voltage swell & 390 & $4.0 * e 6 / 10^{5}$ & 40 \\
Permissible limit of voltage sag & 260 & $11 * e 6 / 10^{5}$ & 11 \\
\hline
\end{tabular}

length decomposed in 6th level using same mother wavelet function $\mathrm{db} 2$ and coefficients energy of cD6 is calculated. Permissible variation in reference signal is considered and the entire procedure is repeated to calculate lower and upper threshold settings. Table 1 is listing the wavelet energy for different cases which helps in deciding lower and upper threshold settings.

\section{Schematic Diagram of System, Results and Discussions}

A schematic diagram of grid connected WECS consists of 3- $\emptyset$ PMSG, full-bridge rectifier, DC-link capacitor, a 3- $\emptyset$ IGBT based full-bridge inverter, critical load, LCL filter, transformer, and circuit breaker and 400 volt, $50 \mathrm{~Hz}$ ac source is shown Figure 8. The system parameters used in simulation are given in Table 2. Simulation model of the system is developed in MATLAB/simulink environment. All the values given in Table 2 have been calculated during mathematical modelling of WECS and grid connected WECS.

5.1. Before Fault. Figure 9 shows the output voltages under normal grid condition. It shows that the implemented control method of voltage source inverter is maintaining the output in desired form. Figure 10 shows load voltage and load current under normal grid condition.

5.2. During Fault. It can be seen from Figure 11 that, in case of fault in phase $\mathrm{B}$, grid voltages of phase $\mathrm{A}$ and phase $\mathrm{C}$ have
TABLE 2: Design parameters for simulation.

\begin{tabular}{lcc}
\hline Description & $\begin{array}{c}\text { Symbolic } \\
\text { representation }\end{array}$ & Value \\
\hline Capacitor & $C_{\mathrm{dc}}$ & $2200 \mu \mathrm{F}$ \\
DC-link voltage & $V_{\mathrm{DC}}$ & 650 volts \\
AC output voltage & $V_{s}$ & 230 volts rms \\
AC output frequency & $f$ & $50 \mathrm{~Hz}$ \\
Inverter side filter inductor & $L_{1}$ & $0.2 \mathrm{mH}$ \\
Grid side filter inductor & $L_{2}$ & $0.1 \mathrm{mH}$ \\
Filter capacitor & $C_{1}$ & $10 \mu \mathrm{F}$ \\
Inverter switching frequency & $f_{s}$ & $3 \mathrm{kHz}$ \\
\hline
\end{tabular}

been inceased. Grid fault occurs at $t=0.45 \mathrm{sec}$ and continues till $t=0.7 \mathrm{sec}$. Monitoring algorithm is constantly monitoring the grid condition. Such cases must be detected and reported to utility intactive inverter at the earliest so that supply to critical load will be continued by intentional islanding of WECS. The load is supplied from WECS and grid current is zero in case of grid fault. Source current and load currents (local and shared load both) which are now supplied from WECS in case of grid not present can be seen from Figure 12.

Grid fault causes voltage variations in all the three phases. Voltage waveform of all the three phases and corresponding coefficients energy plots are displayed in Figures 13, 14, and 15, respectively, in red, green (istead of yellow for improved visibility), and blue color for phase $\mathrm{A}$, phase $\mathrm{B}$, and phase $\mathrm{C}$. Wavelet energy is normalized as calculated value has very 


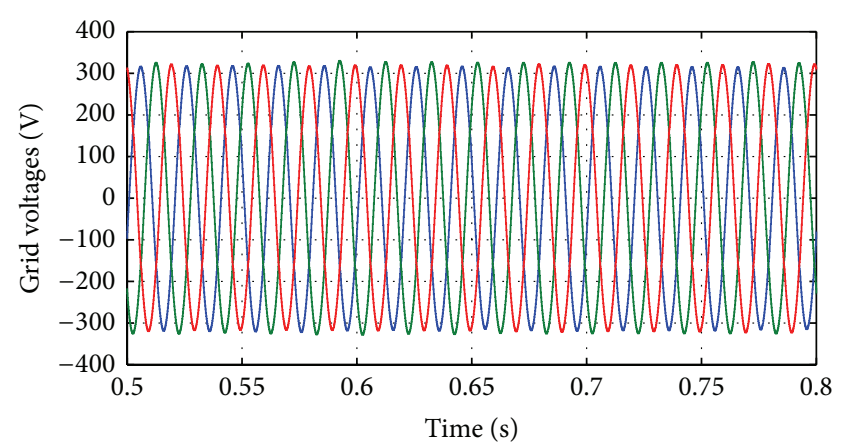

$-V_{a}$
$-V_{b}$

$-V_{c}$

FIGURE 9: Three-phase grid voltages before fault.

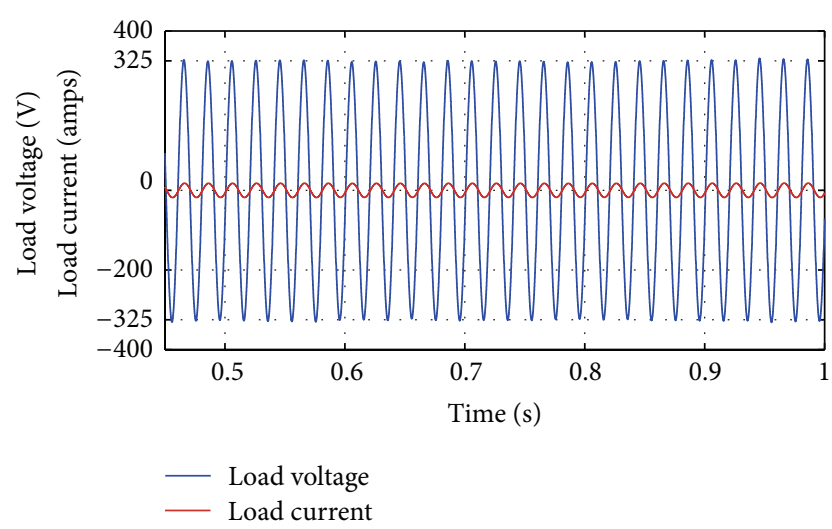

FIGURE 10: Output waveform of load voltage and load current before fault.

large value and even a large change in coeficients energy cannot be clearly observed from actual plots of wavelet energy. Grid voltages and corresponding coefficients energy plot are graphical representation of change in wavelet coefficients energy in case of grid disturbances. Threshold level with calculated threshold further helps in transition of modes from grid connected to stand-alone and vice versa.

At $t=0.45 \mathrm{sec}$ grid fault occurs; wavelet based monitoring algorithm detects it at $0.48 \mathrm{sec}$ and changes the mode of WECS from grid connected to stand-alone. Many distribution systems use autoreclosing to clear temporary faults and hence it is essential to detect grid faults before the autorecloser operates to avoid out phase reclosing. Grid fault causes voltage variations in all the three phases which can be observed clearly in Figure 16.

Transition of mode from grid connected to stand-alone occured at $0.48 \mathrm{sec}$ which is the total time taken by the proposed method in detection of grid disturbance and further isolate the WECS by operting circuit breaker which disconnects it from grid. When mode trasition occurs, controller of VSI changes its mode and continues to feed power to the load connected to it. The grid monitoring algorithm detects fault and changes mode of operation from grid connected

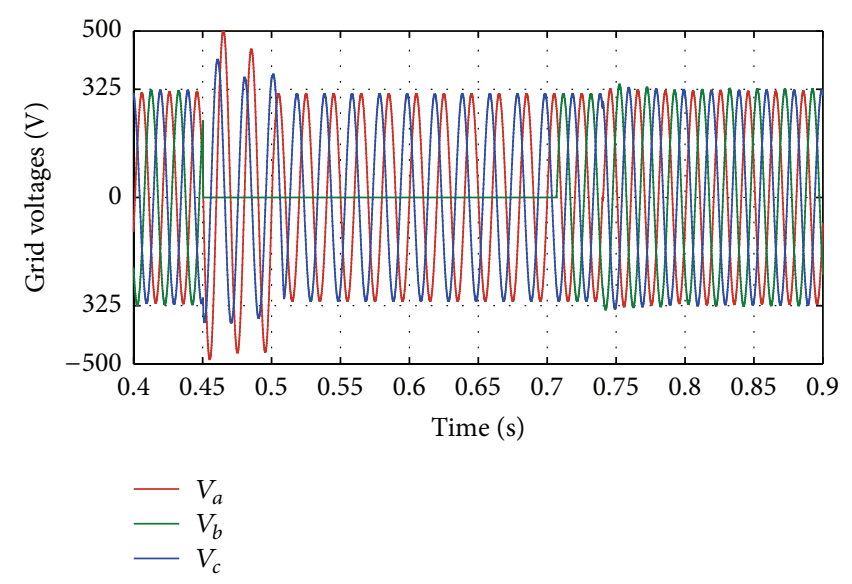

FIGURE 11: Three-phase grid voltages during disturbance.

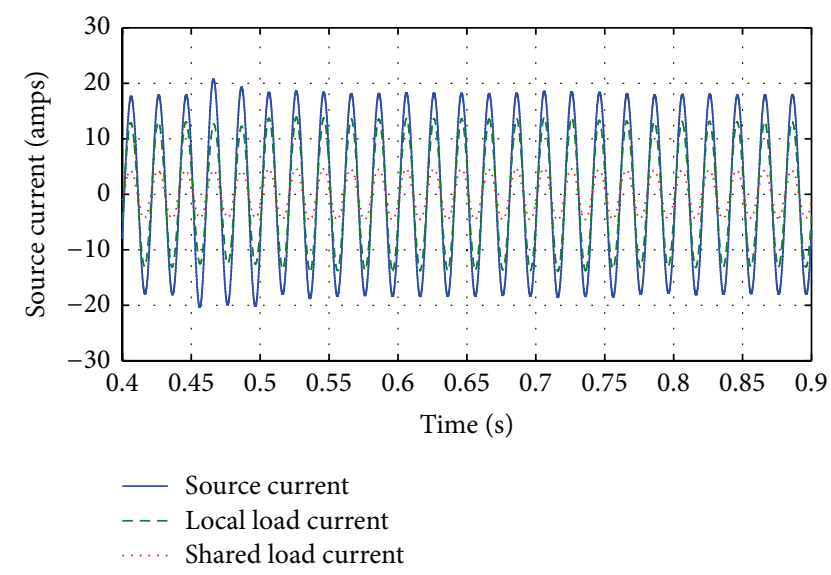

FIGURE 12: Source current, local load current, and shared load current.

mode to stand-alone mode at $0.48 \mathrm{sec}$ when circuit breakers opens. The timings of mode change and circuit breaker status (1 means WECS grid connected, 0 means disconnected from grid) can be seen from Figure 17. Figure 18 displays the lower threshold value due to which transition occurs.

Grid voltage of all the phases and corresponding coefficients energy plots are shown in Figures 19, 20, and 21, respectively, of phase A, phase B, and phase C. Grid voltages and corresponding coefficients energy plot are graphical representation of wavelet coefficients energy. A small change in voltages at load terminal (PCC) can be observed in the signal and associated wavelet energy plot in Figures 19, 20, and 21 that is due to change of load because of mode transition. WECS is now fed power to critical load and local loads connected to it. Monitoring is still continued at PCC to check for grid condition. On the basis of threshold value of wavelet energy transition occurs from stand-alone mode to grid connected mode, which can be observed from Figures 19(a) and 19(b) at time $0.7 \mathrm{sec}$ when fault is cleared.

The power conditioning module for both the modes is based space vector pulse width modulation. Instead of conventional SVM, triangular carrier based SVM is used to 


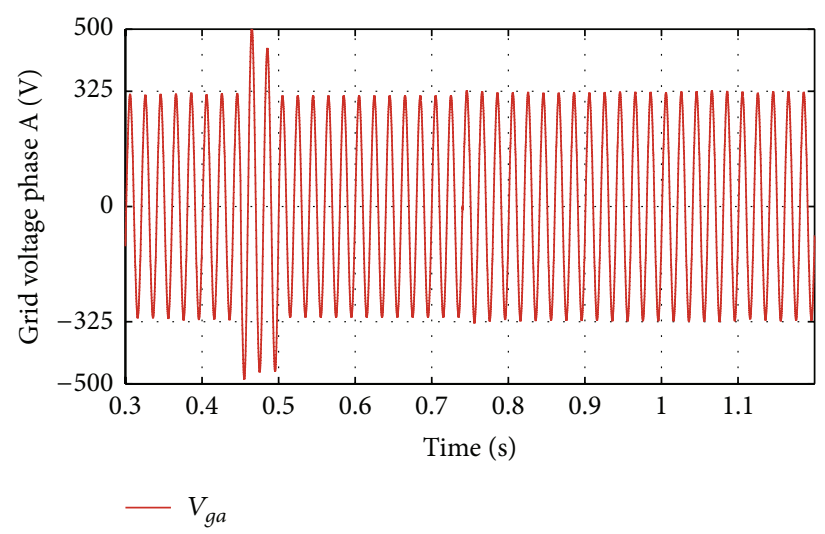

(a)

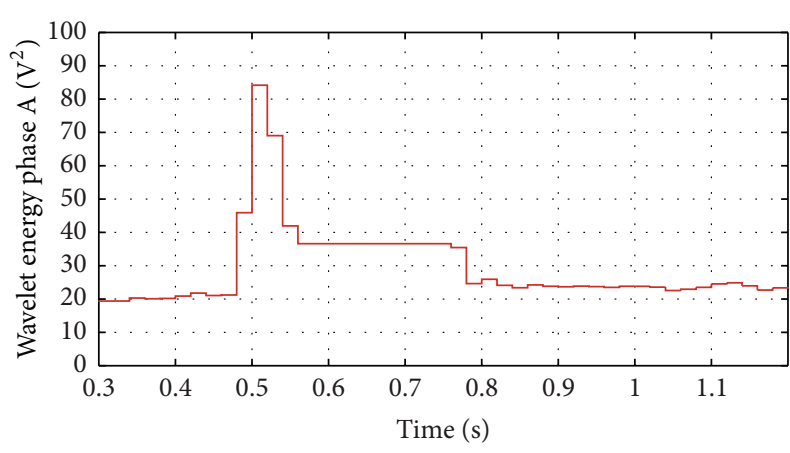

$-E V_{a}$

FIGURE 13: (a) Voltage signal and (b) corresponding wavelet energy plot of phase A.

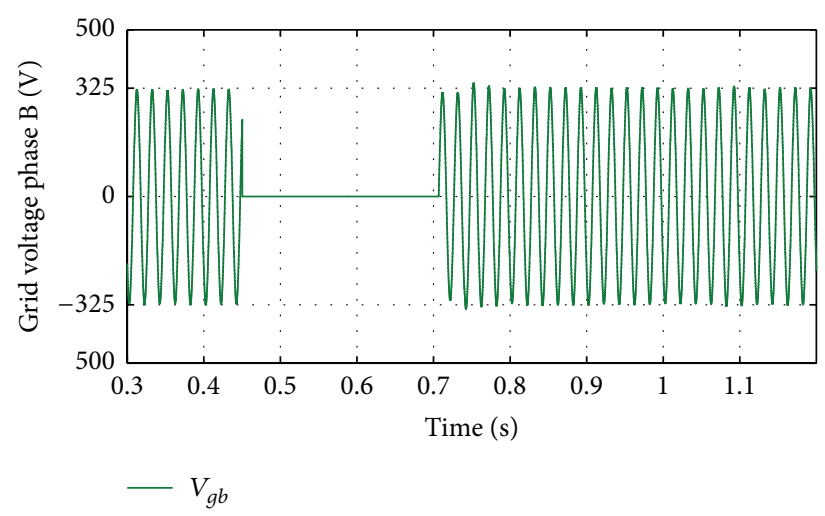

(a)

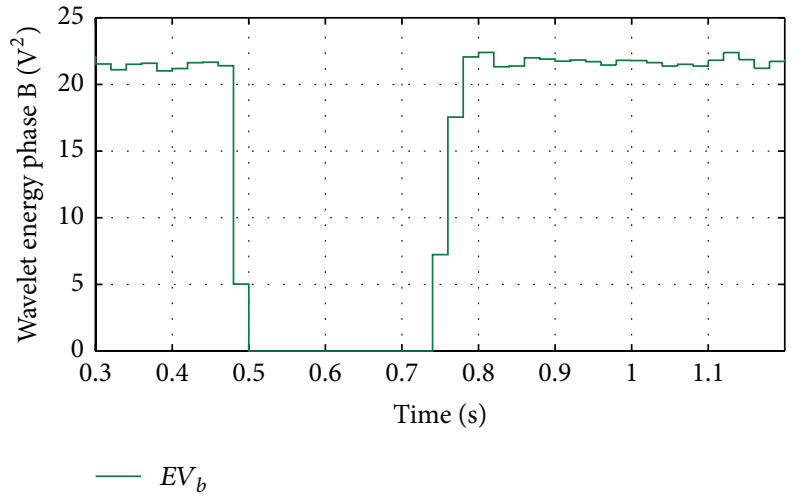

(b)

FIGURE 14: (a) Voltage signal and (b) corresponding wavelet energy plot for fault in phase B.

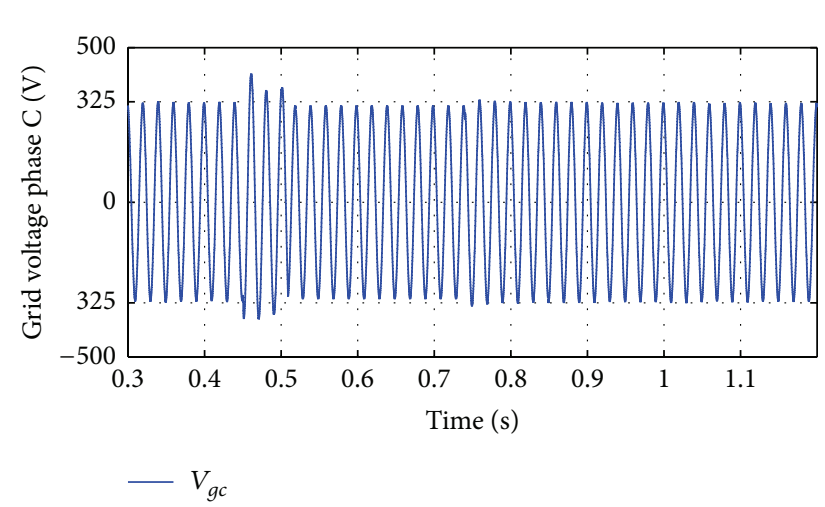

(a)

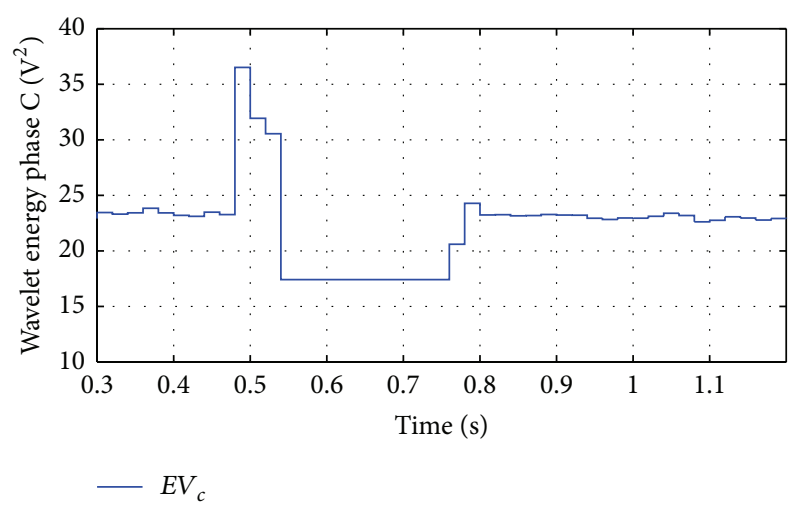

(b)

FIGURE 15: (a) Voltage signal and (b) corresponding wavelet energy plot of phase C.

reduce computation burden as sector determination is not required in implementation. The benefits of using DWT and wavelet energy based algorithm are accurate detection of start and end time of occurrence of any event or varaitions. Accurate and quick detection can also be helpful for protection of equipments as well as for the safety and stability of the system.

\section{Generation of Gate Pulses for Single Phase Bridge Inverter Using FPGA}

In grid connected mode as well as in stand-alone mode of WECS, space vector pulse width modulation scheme has been used for inverter control. Its performance is checked 


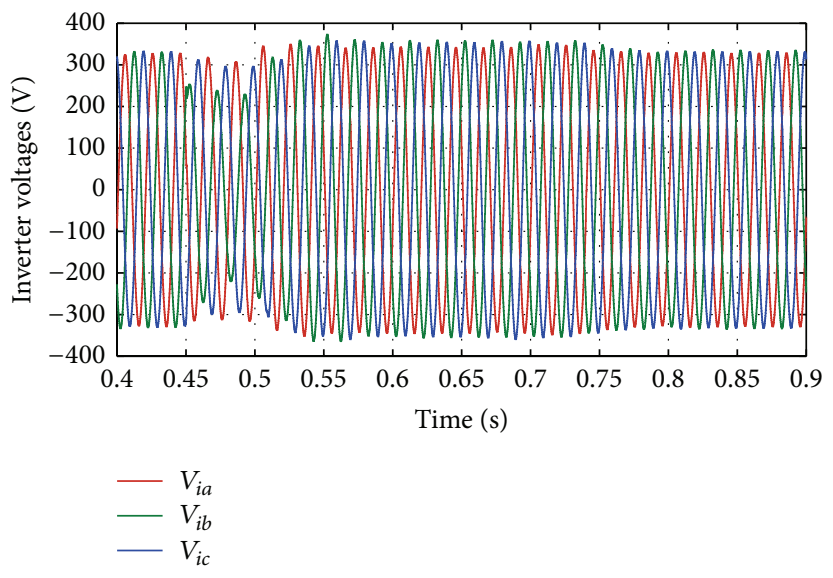

Figure 16: Three-phase voltages at PCC.

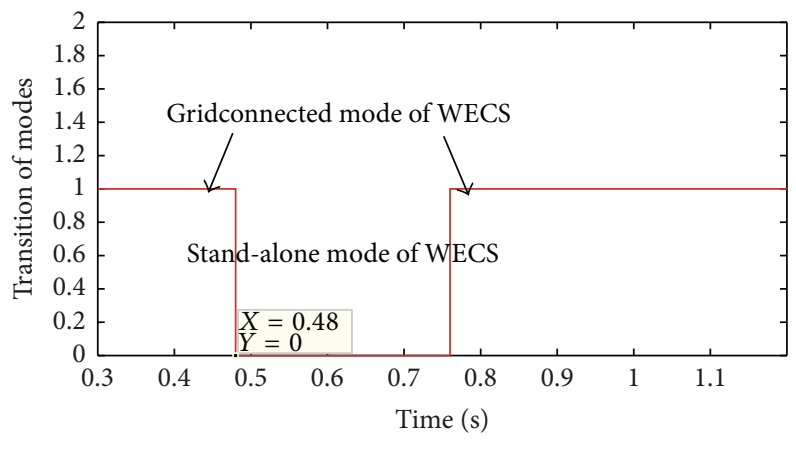

— Circuit breaker status (on/off)

FIgURE 17: Transition of modes.

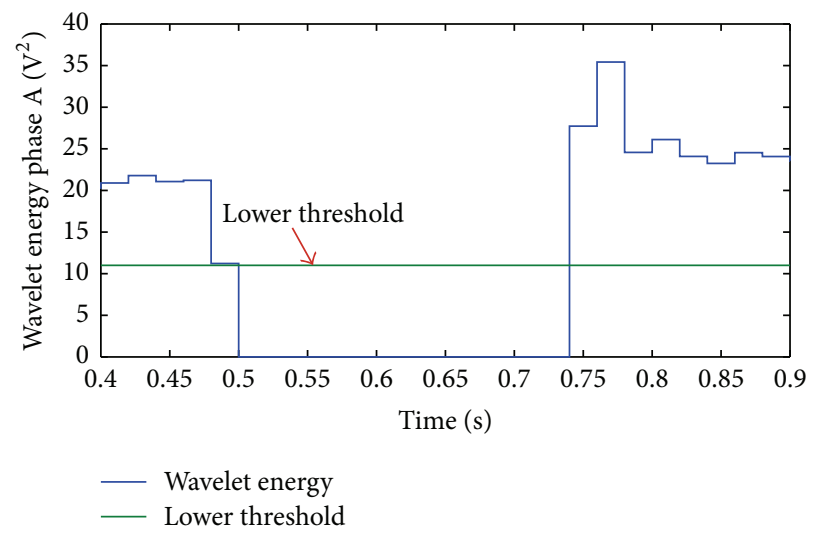

FIgURE 18: Threshold settings.

using FPGA with Altium NB 3000, Xilinx Spartan 3AN processor. Step-by-step procedure for generating inverter gate pulse is shown in Figure 22. XILINX ISE design suite 14.5 is used for model based design for PWM pulse generation for single phase bridge inverter and Altium designer software is used for FPGA project design. Number of steps has been performed for bit file generation using Altium design software. It generates the programming file that is required for downloading the design to the physical device. A detailed procedure for project design using FPGA is given in [21].

Schematic diagram to test SVPWM control method for generating gate pulses using FPGA is shown in Figure 23.

Sine waveform and triangular carrier waveform of frequency $500 \mathrm{~Hz}$ are given as input by ADC-SPI port and inverter gate pulses are obtained by user I/O port which is shown in Figures 24 and 25, respectively. 


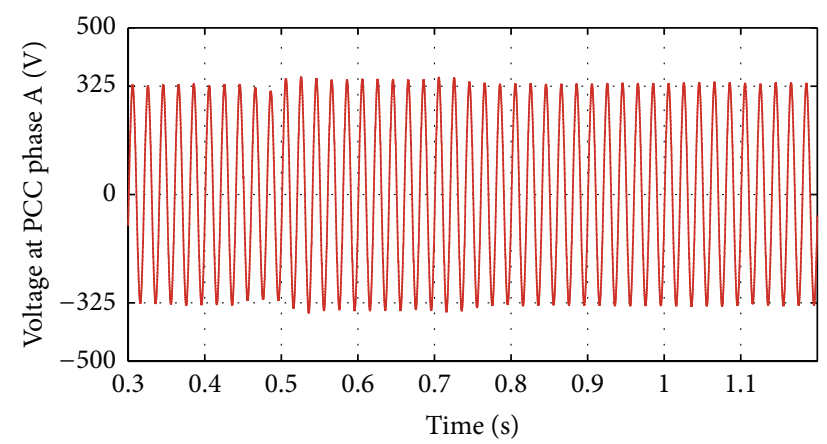

$-V_{i a}$

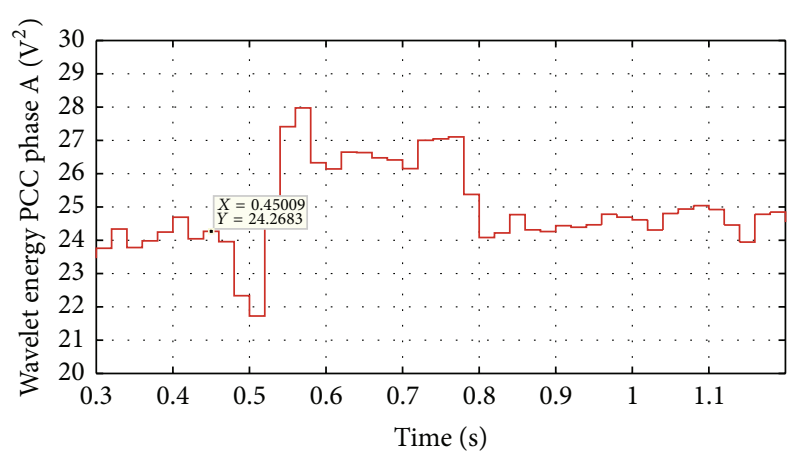

$-E V_{a}$ at PCC

(a)

(b)

FIGURE 19: (a) Voltage signal and (b) wavelet energy plot at PCC for phase A.

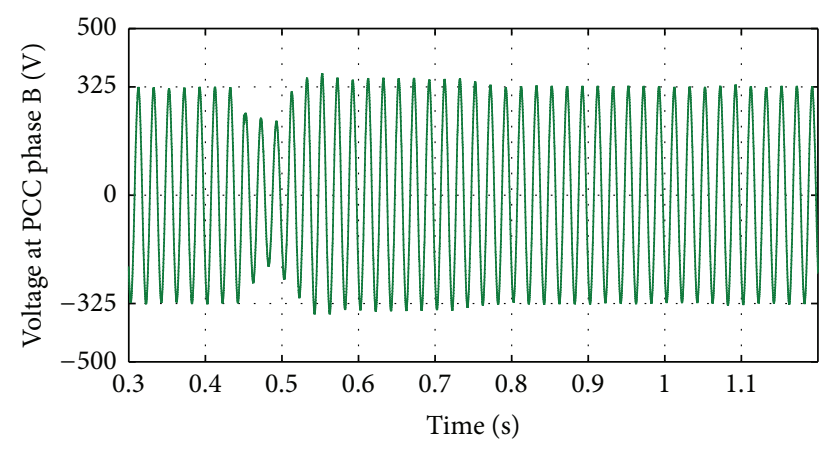

$-V_{i b}$

(a)

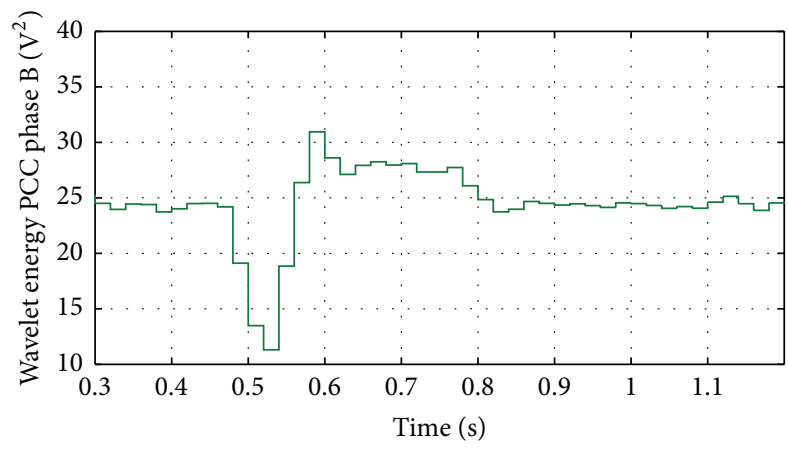

$-E V_{a}$ at PCC

(b)

FIGURE 20: (a) Voltage signal and (b) wavelet energy plot at PCC for phase B.

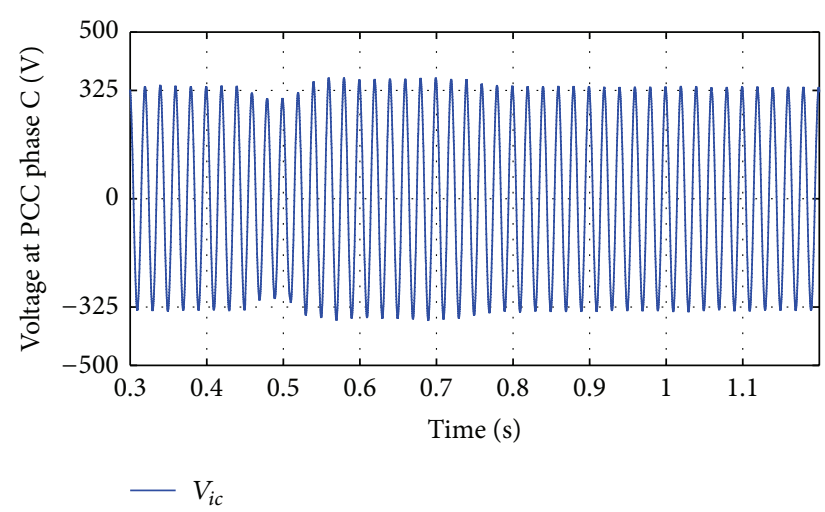

(a)

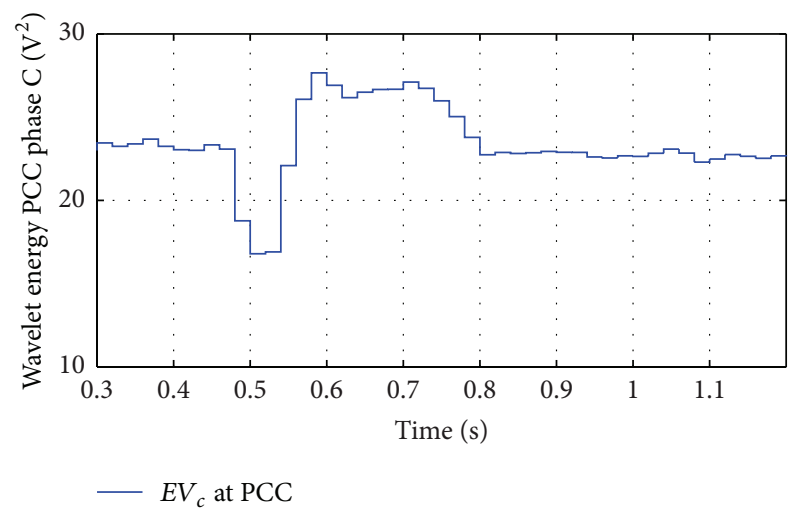

(b)

FIGURE 21: (a) Voltage signal and (b) wavelet energy plot at PCC for phase C.

\section{Conclusions}

The proposed method has been implemented for a $10 \mathrm{~kW}$ wind energy conversion system with rectifier-inverter interface which can work in grid connected mode as well as in stand-alone mode. The benefit of the used control scheme is that switching between the two operating modes happens automatically on the basis of output of energy function. The most important feature of the system is its adaptability to work in both of the operating modes properly. PLL is used for synchronization in grid connected mode. Simulation results demonstrate the working and transition between the modes of WECS in only $3 \mathrm{~ms}$ time and no transients appear during transition of modes. 


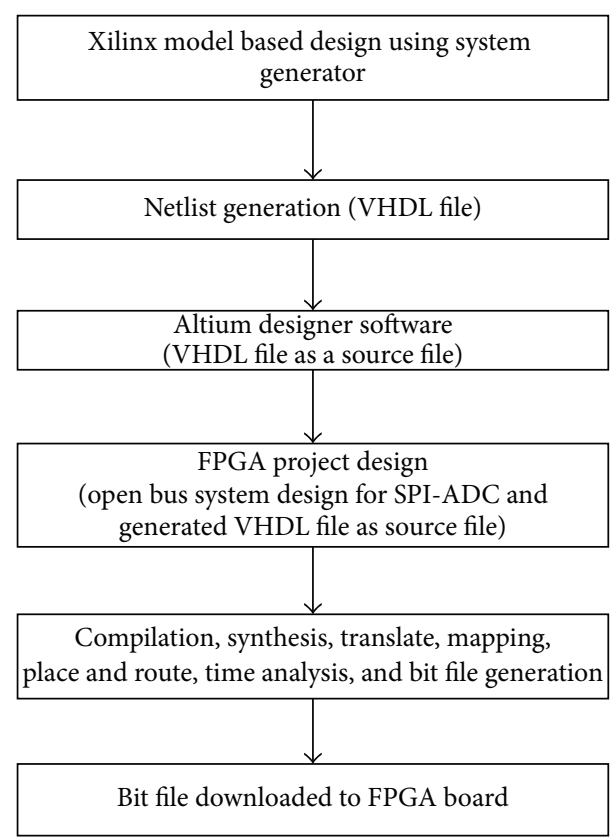

FIGURE 22: Step-by-step procedure for inverter gate pulse generation using FPGA.

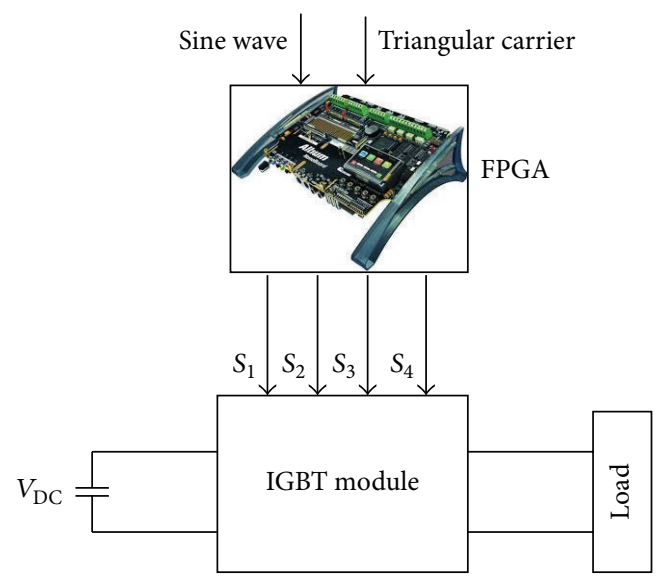

FIGURE 23: Schematic diagram for hardware setup.

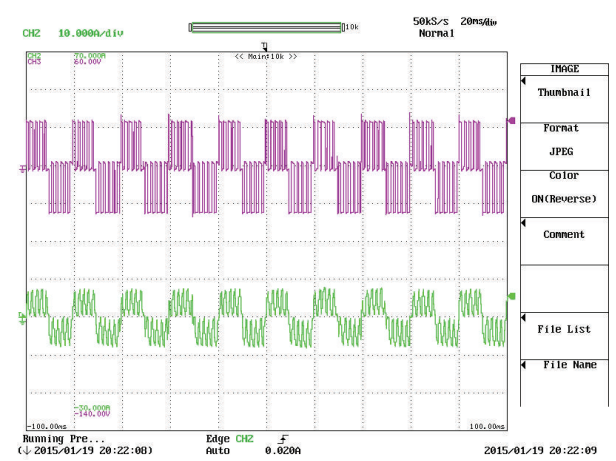

Figure 24: Load voltage and load current through RL load.

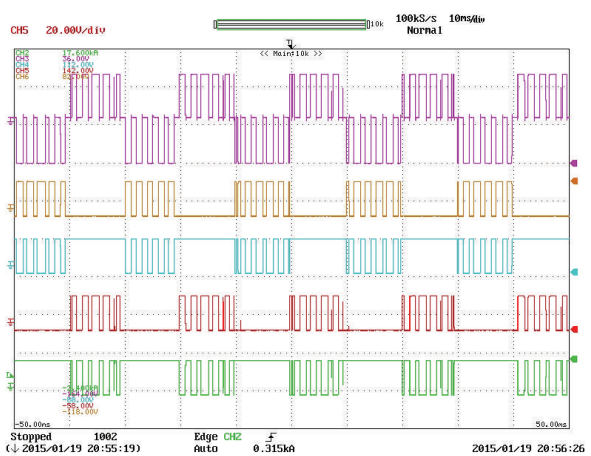

FIGURE 25: Inverter output voltage and output gate pulses for single phase bridge inverter.

The tests concluded that detection method has the following properties.

(i) Detect grid disturbances event in just $3 \mathrm{~ms}$.

(ii) Accurate detection and quick transition maintain the power quality and supply uninterrupted power to critical load in case of grid outage.

(iii) It is suitable for detection of steady state and transient state disturbances both.

\section{Conflict of Interests}

The authors declare that there is no conflict of interests regarding the publication of this paper.

\section{References}

[1] R. Teodorescu, F. Iov, and F. Blaabjerg, "Flexible development and test system for $11 \mathrm{~kW}$ wind turbine," in Proceedings of the IEEE 34th Annual Power Electronics Specialists Conference, pp. 67-72, June 2003.

[2] N. A. Orlando, M. Liserre, R. A. Mastromauro, and A. Dell'Aquila, "A survey of control issues in pmsg-based small wind-turbine systems," IEEE Transactions on Industrial Informatics, vol. 9, no. 3, pp. 1211-1221, 2013.

[3] R. Teodorescu and F. Blaabjerg, "Flexible control of small wind turbines with grid failure detection operating in stand-alone and grid-connected mode," IEEE Transactions on Power Electronics, vol. 19, no. 5, pp. 1323-1332, 2004.

[4] B. Singh and G. K. Kasal, "Solid state voltage and frequency controller for a stand alone wind power generating system," IEEE Transactions on Power Electronics, vol. 23, no. 3, pp. 1170-1177, 2008.

[5] A. Milczarek and M. Malinowski, "Monitoring and control algorithms applied to small wind turbine with grid-connected/ stand-alone mode of operation," Przeglad Elektrotechniczny, vol. 88, pp. 18-22, 2012.

[6] S. I. Jang and K. H. Kim, "An islanding detection method for distributed generations using voltage unbalance and total harmonic distortion of current," IEEE Transactions on Power Delivery, vol. 19, no. 2, pp. 745-752, 2004.

[7] S. I. Jang and K. H. Kim, "A new islanding detection algorithm for distributed generations interconnected with utility networks," in Proceedings of the 8th IEE International Conference 
on Developments in Power System Protection, vol. 2, pp. 571-574, IET, April 2004.

[8] S.-I. Jang and K.-H. Kim, "Development of a logical rulebased islanding detection method for distributed resources," in Proceedings of the IEEE Power Engineering Society Winter Meeting, vol. 2, pp. 800-806, January 2002.

[9] J. W. Resende, M. L. R. Chaves, and C. Penna, "Identification of power quality disturbances using the MATLAB wavelet transform toolbox," in Proceedings of the 4th International Conference on Power Systems Transients (IPST '01), Rio de Janeiro, Brazil, June 2001.

[10] Ç. Kocaman and M. Özdemir, "Comparison of statistical methods and wavelet energy coefficients for determining two common PQ disturbances: sag and well," in Proceedings of the 6th International Conference on Electrical and Electronics Engineering (ELECO '09), pp. I80-I84, November 2009.

[11] P. K. Ray, N. Kishor, and S. R. Mohanty, "Islanding and power quality disturbance detection in grid-connected hybrid power system using wavelet and S-transform," IEEE Transactions on Smart Grid, vol. 3, no. 3, pp. 1082-1094, 2012.

[12] R. Tirumala, N. Mohan, and C. Henze, "Seamless transfer of grid-connected PWM inverters between utility-interactive and stand-alone modes," in Proceedings of the 17th Annual IEEE Applied Power Electronics Conference and Expositions (APEC '02), pp. 1081-1086, March 2002.

[13] A. Timbus, M. Liserre, R. Teodorescu, P. Rodriguez, and F. Blaabjerg, "Evaluation of current controllers for distributed power generation systems," IEEE Transactions on Power Electronics, vol. 24, no. 3, pp. 654-664, 2009.

[14] S. W. Mohod and V. A. Mohan, "Power quality issues and it's mitigation technique in wind energy generation," in Proceedings of the 13th International Conference on Harmonics and Quality of Power (ICHQP '08), Wollongong, Australia, October 2008.

[15] C. N. Bhende, S. Mishra, and S. G. Malla, "Permanent magnet synchronous generator-based standalone wind energy supply system," IEEE Transactions on Sustainable Energy, vol. 2, no. 4, pp. 361-373, 2011.

[16] J. M. Carrasco, L. G. Franquelo, J. T. Bialasiewicz et al., "Powerelectronic systems for the grid integration of renewable energy sources: a survey," IEEE Transactions on Industrial Electronics, vol. 53, no. 4, pp. 1002-1016, 2006.

[17] C. L. Anooja and N. Leena, "Single phase shunt active filter with fuzzy controller for harmonic mitigation," International Journal of Scientific \& Engineering Research, vol. 4, no. 9, pp. 445-451, 2013.

[18] L. G. B. Rolim, D. R. Da Costa Jr., and M. Aredes, "Analysis and software implementation of a robust synchronizing PLL circuit based on the pq theory," IEEE Transactions on Industrial Electronics, vol. 53, no. 6, pp. 1919-1926, 2006.

[19] B. Jain, T. Jain, S. Jain, and R. K. Nema, "Power quality improvement of an isolated wind power generation system," IOSR Journal of Electrical and Electronics Engineering, vol. 9, no. 3, pp. 33-50, 2014.

[20] K. Zhou and D. Wang, "Relationship between space-vector modulation and three-phase carrier-based PWM: a comprehensive analysis," IEEE Transactions on Industrial Electronics, vol. 49, no. 1, pp. 186-196, 2002.

[21] X. Computation, "Getting started with the Xilinx Virtex-6 FPGA MI-605 evaluation Kit,” 2010. 


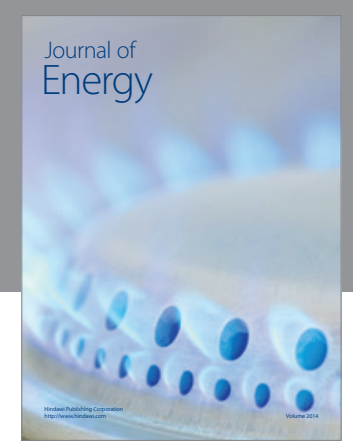

Journal of

Industrial Engineering
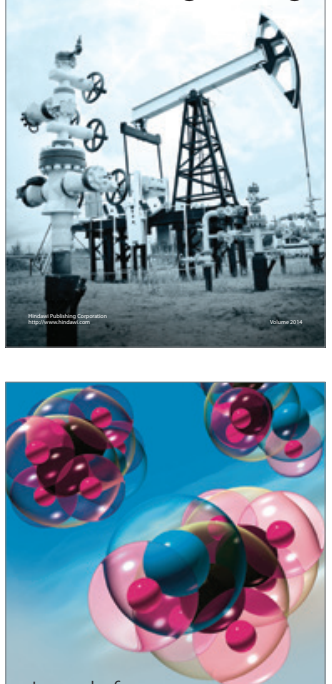

Fuels
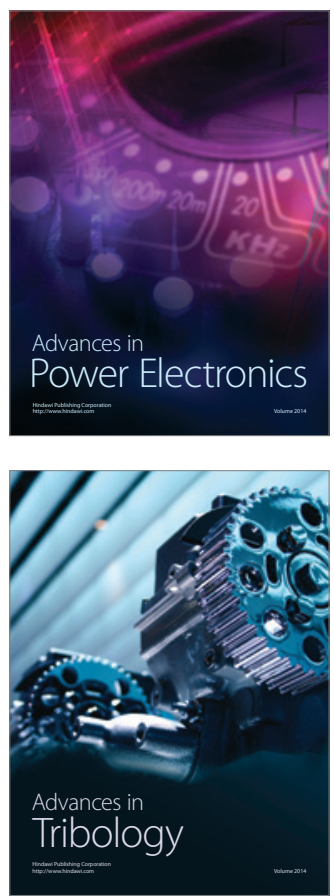

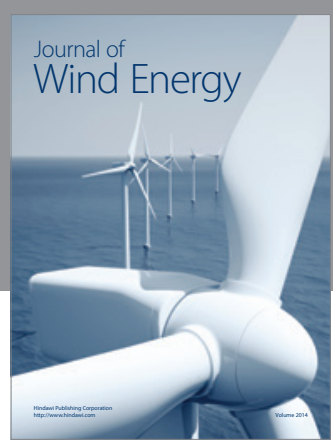

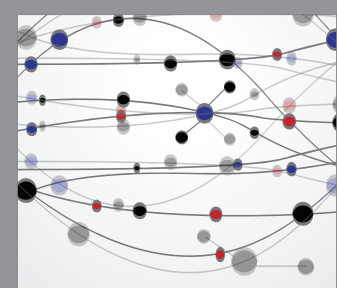

The Scientific World Journal

Submit your manuscripts at http://www.hindawi.com

Journal of

Structures
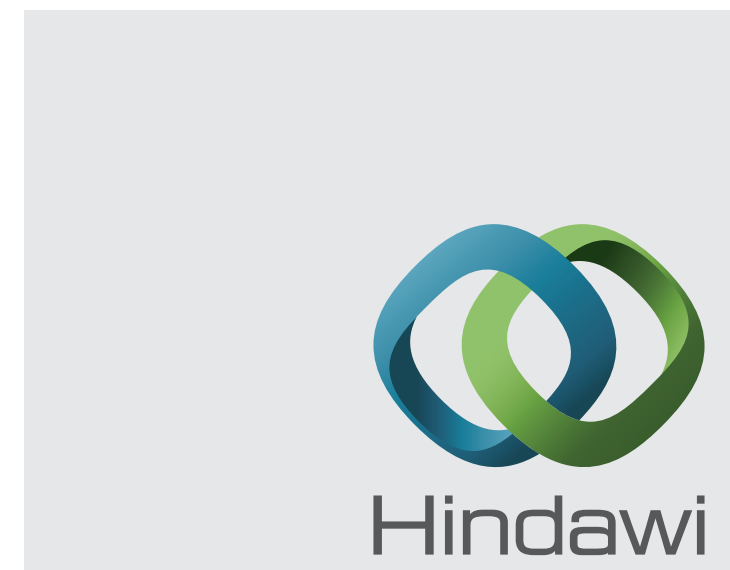

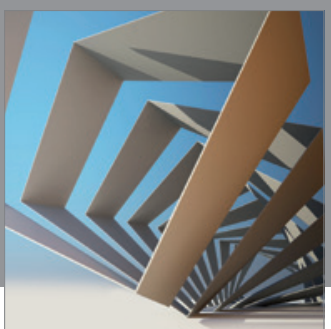

Rotating

Machinery
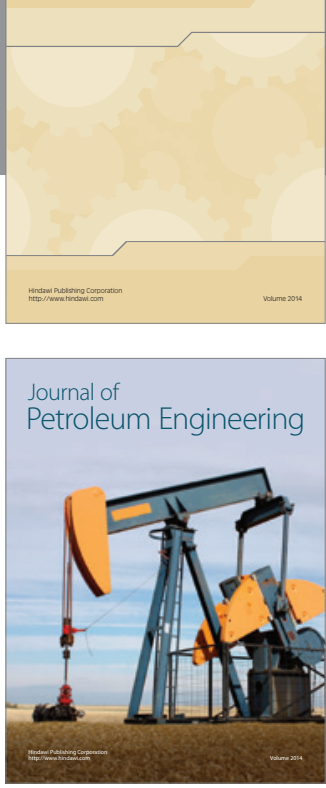

Journal of

Solar Energy
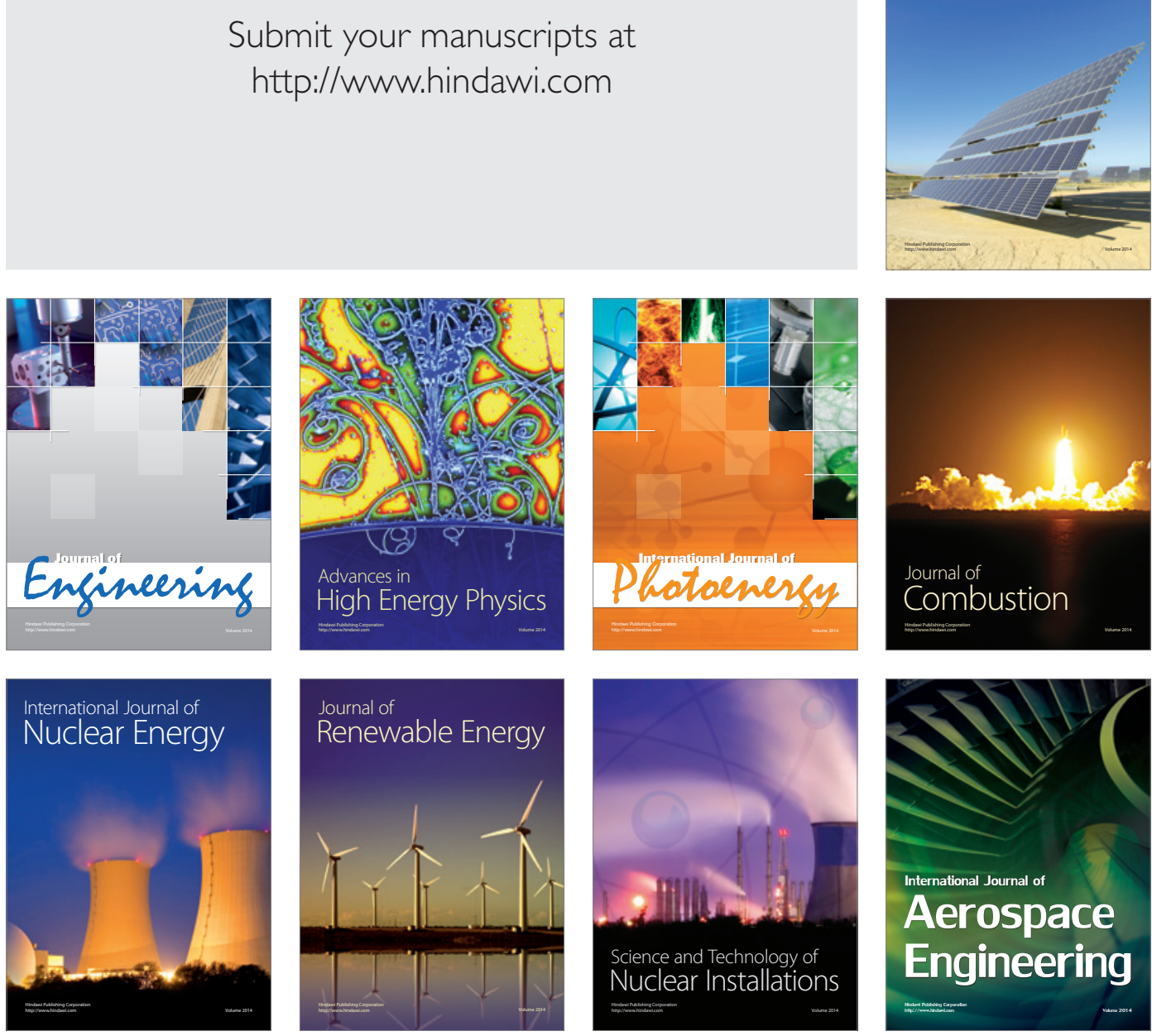